\title{
UM MODERNISTA BRASILEIRO NAVEGANDO PELAS ÁGUAS DO RIO DA PRATA
}

\author{
A BRAZILIAN MODERNIST SAILING LA PLATA RIVER
}

\author{
Mônica Gomes da Silva ${ }^{1}$ \\ 1 Universidade Federal do Recôncavo da Bahia (UFRB), Cruz das Almas, BA, Brasil \\ monicagomessilva@yahoo.com.br
}

Recebido em: 25 abr. 2018

Aceito em: 22 mai. 2018

Resumo: Em 1935, a convite do jornal argentino Crítica, organiza-se a visita de uma comitiva de intelectuais brasileiros à região do Rio da Prata. Dentre os intelectuais convidados, encontrava-se o escritor António de Alcântara Machado, um dos protagonistas do movimento modernista. A partir desta, que foi sua última viagem internacional, publicou-se uma série de artigos para o Diário da Noite e $O$ Jornal. Discutem-se, neste artigo, as imagens construídas sobre a região rio-platense pelo jornalista paulistano. O cronista analisa a experiência da modernidade em Montevidéu e Buenos Aires, sem abandonar o humor e a prosa ágil que o singulariza na literatura do período. É evidente a admiração pelo aparente progresso material e cultural das cidades platinas. Nota-se um texto dissonante da representação construída, por exemplo, pelos próprios colaboradores do periódico Crítica, publicação promotora da viagem. Enquanto jornalistas como Roberto Arlt descrevem uma Buenos Aires babélica e marginal, o escritor brasileiro se detém em tópicos construtores da nacionalidade argentina e delineia uma imagem ordeira para o espaço urbano. A fim de abordar o conceito de civilização e a visão refratária do modernista sobre o fenômeno urbano bonaerense, parte-se do estudo de Beatriz Sarlo (2010), cujo conceito de cultura de mescla traduz o processo complexo de modernização na Argentina e o processo de expansão do mercado cultural.

Palavras-chave: Alcântara Machado. Civilização. Crônica. Rio da Prata.

Abstract: In 1935, invited by the Argentine newspaper Crítica, an entourage with Brazilian intellectuals visited the region of La Plata River. Among the intellectuals invited, was the writer António de Alcântara Machado, one of the leading figures of the modernist movement. As a result of that trip, a number of articles for the newspapers Diário da Noite and $O$ Jornal were published. In this paper, I discuss the images of La Plata River zone, constructed by the author. The chronicler analyzes the experience of modernity in Montevideo and Buenos Aires, without abandoning the humor and agile prose that singularized it in the literature of the period. It is evident the admiration for the apparent material and cultural progress of La Plata River zone. It can be observed that his writing differs from the representation constructed, for instance, by other columnists of the newspaper Crítica, the journal that fostered the trip. Whereas journalists such as Roberto Arlt describe Buenos Aires as Babelic and marginal, the Brazilian writer focuses on topics that construct the Argentine nationality and outlines a clean and organized image of the urban space. In order to approach the concept of civilization and the refractory perspective of the modernist author concerning the urban phenomenon of Buenos Aires, this paper is based on the studies of Beatriz Sarlo (2010), whose concept of culture of mixture explains the complex process of modernization in Argentina and the expansion process of the cultural market.

Keywords: Alcântara Machado. Civilization. Chronicle. La Plata River.

\section{Introdução}

Em fevereiro de 1935, o jornal argentino Crítica (1913-1963) promoveu uma missão de intelectuais brasileiros à região do Rio da Prata. Os jornalistas Agrippino 
Grieco (1888-1973), António Castilho de Alcântara Machado D'Oliveira (1901-1935), Múcio Carneiro Leão (1898-1939) e Renato de Almeida (1895-1981) compuseram a comitiva divulgada, efusivamente, pela imprensa daqui. Em anúncio da viagem, Guillermo Hohagen, organizador da missão e representante do jornal Crítica no Brasil, revela a dinâmica diplomática e política que impulsiona a pretensa aproximação entre os dois países. Inclusive, o periódico portenho apóia, como sinal de cooperação e fortalecimento, a candidatura ao Prêmio Nobel da Paz do brasileiro Afonso Arinos de Mello Franco (1905-1990).

Urdida entre figuras de relevância no cenário intelectual brasileiro, a iniciativa ocorre num momento de grandes instabilidades, ideológicas e políticas, decorrentes da grave crise econômica que atinge a década de 1930. Tanto o Brasil, quanto a Argentina, reagiam a rupturas republicanas traumáticas. No Brasil, o início da Era Vargas implodiu a República Velha e se vivia um incremento significativo dos setores urbanos, com um acelerado crescimento industrial, ao mesmo tempo em que se experimentava uma das piores crises financeiras e produtivas da nação. Na Argentina, ocorre a destituição do presidente argentino Hipólito Yrigoyen (1852-1933) por José Félix Uriburu (1868-1932), com a posterior ascensão de Augustín Pedro Justo (18761943), general que se aproxima da ditadura Vargas.

No caso argentino, destaca-se o papel desempenhado pelo jornal Crítica, cujo apoio ao golpe militar demonstra o poder emergente dos meios de comunicação no processo político. Firma-se a possibilidade de construção do discurso histórico à revelia dos acontecimentos: "Luego del golpe del 6 de septiembre de 1930, el diario - que apoyaba a Uriburu contra Yrigoyen y tituló en su tapa 'Revolución' - se atribuyó la venta de 800.000 ejemplares." (SAÍTTA, 1998, p. 35).

O jornal Crítica constrói "las bases del periodismo masivo y comercial" (idem) na Argentina, através da inovação dos aspectos gráficos, a composição de manchetes e a diversificação da matéria jornalística, com destaque para as notícias de crimes, as reportagens esportivas e as notas sociais. Almejava-se, por parte do periódico, alcançar um público vasto e variado ao mesmo tempo: "Crítica quería abarcar todo y a todos: tenía la idea de incorporar a todos los sectores del público." (ibidem). Esse desejo de influir em diversos estratos da sociedade faz com que o jornal atenda a interesses distintos, indo das notícias sensacionalistas à publicação de grandes 
escritores e poetas em suplementos literários, além de atuar, incisivamente, no cenário político argentino.

Não é surpreendente, portanto, a iniciativa do veículo em criar pontes com os demais países da América do Sul, estabelecendo uma agenda política, dado o seu amplo âmbito de atuação. Articula-se o "sentido fraternal da Argentina no seu desejo de cooperar com todas as nações da América" (HOHAGEN apud MACHADO, 1983, p. 294) à vocação cultural do veículo. Elege-se, assim, "um grupo de homens de letras do Brasil" (idem) para transmitir a experiência da modernidade na região rio-platense.

O objetivo da viagem consistia em aproximar as "pátrias de Sarmiento e Euclides da Cunha" a fim de conhecer as características comuns que pudessem "construir a civilização 'deste outro lado'” (HOHAGEN apud MACHADO, 1983, p. 294). A seleção de um "grupo de intelectuais [...] integrados no espírito de seu país no concerto das nações" (idem) deixa entrever a necessidade de "unir mais e mais a nossa América" (idem), em um tempo de fortes totalitarismos. Na busca desse denominador comum, reitera-se o confronto interno de ambas as nações, a luta entre a "civilização" e a "barbárie", deixando nítido o anseio de alcançar um padrão considerado moderno, avançado. Esta conformação ideológica repercute nos relatos decorrentes da viagem pelo Uruguai e pela Argentina, assim como o panorama turbulento da década, através dos tópicos do domínio do espaço natural, o ideal de civilização e a adesão a novas técnicas como marca de progresso.

Por outro lado, o anúncio de Guillermo Hohagen reforça a visão de desconhecimento mútuo entre os dois países. O distanciamento cultural entre Argentina e Brasil aparece, igualmente, em depoimento acerca da viagem de um dos integrantes da comitiva. Múcio Leão deixa explícito, tanto a curiosidade argentina a respeito da classe intelectual brasileira, quanto o acesso a um território desconhecido por parte dos brasileiros. Aparece, no depoimento do jornalista, os contornos indefinidos da atuação desses intelectuais em terras bonaerenses, quais seriam suas atribuições e espaços de interlocução:

Essa viagem foi feita a convite de Crítica, um dos grandes jornais da Argentina. Queria Crítica talvez, ter a certeza de que no Brasil existe gente que pensa e que escreve. Eu não pude perceber, até agora, que vantagens tem um país em possuir uma espécie de gente tão desventurada, que chega a esse excesso - o de escrever e o de pensar; e percebo ainda menos que vantagem tem outro país em verificar que no território do seu vizinho lavra, de fato, uma tão triste e lastimável espécie de enfermidade. Mas, enfim, Crítica teve essa curiosidade malsã e convidou-nos para um passeio a Buenos Aires. (LEÃO, 1936, p. 139). 
Prosseguindo o depoimento, o jornalista se refere à "exibição tão nacional de fazer discursos" (LEÃO, 1936, p. 140) em Buenos Aires, como uma das possíveis atividades da comitiva. Contudo, além das palavras levadas pelo vento das décadas, chegaram até nós o registro das impressões dessa tentativa de estreitamento cultural entre o Brasil e a região do Rio da Prata: são os artigos publicados no Diário da Noite (1929-1961) e O Jornal (1924-1974) pelo escritor paulistano António de Alcântara Machado, um dos colaboradores mais ativos do Modernismo.

Para analisar as crônicas de A. de A. M. ${ }^{1}$, que são a soma de fatores políticos e culturais tumultuosos, faz-se necessário conhecer alguns dados sobre a trajetória do escritor no movimento modernista e de sua atuação na década de 1930, ainda que sumariamente. Após essa breve apresentação, passamos ao roteiro da viagem do modernista pelo Rio da Prata e cotejaremos suas "impressões" com a experiência argentina da "modernidade periférica".

\section{A. de A. M e a aventura da renovação na literatura brasileira}

A intensa participação de A. de A. M. no Modernismo pode ser constatada através da função de editor de publicações como Terra Roxa ... e Outras Terras (19261927) e a Revista de Antropofagia, na sua primeira dentição (1928-1929), tornando-o um importante articulador do movimento. Também sobressai a atuação do artista que estabelece novos paradigmas para a prosa brasileira. A. de A. M. é um criador atento à dicção e ao espaço urbano paulistanos, ao inaugurar uma relação diversa entre jornalismo e literatura, propondo reciprocidade entre os recursos das duas áreas, sem a prevalência de uma sobre a outra. Segundo Cecília de Lara, as composições dessa primeira fase são marcadas por "uma prosa ágil, dinâmica, original, que dá a característica de um estilo, não ainda definido, antes dele, no modo de escrever

\footnotetext{
${ }^{1}$ Para nos referirmos ao escritor, usaremos as iniciais A. de A. M., a forma mais frequente com a qual assinava suas crônicas. Evitamos um dos problemas que incomodava ao jornalista e que ensejou algumas atribuições equivocadas em sua bibliografia: "Alcântara Machado é meu Pai. Eu sou António de A. M. No sumário figura meu Pai e não eu." (MACHADO, 1997, p. 49).
} 
moderno, pelo movimento que teve início na Semana de Arte Moderna." (LARA, 1983, p. 11).

A estreia literária do escritor ocorre no momento a que se convencionou denominar de "fase heróica" do Modernismo, quando havia intensa resistência às propostas artísticas do grupo. A primeira obra recebe o título de Pathé-Baby (1926) e consiste numa reunião de crônicas sobre a segunda viagem realizada pelo autor à Europa. As crônicas, divulgadas um ano antes pelas páginas do jornal, são reescritas e alcançam um sucesso inesperado, apesar das polêmicas em torno do "estilo seco" e do humor rascante.

Sente-se, nesses primeiros textos, a contribuição das vanguardas artísticas no que diz respeito à busca das inovações tecnológicas como fonte para a renovação da escrita. O ineditismo da proposta consiste em incorporação de recursos gráficos realizando "uma unidade inseparável entre desenho e literatura." (LARA, 1983, p. 11). Os novos meios de comunicação, como o telefone e o telégrafo, e as novas formas de arte audiovisual, como o cinema, representam não apenas a integração à modernidade como tema, mas também uma nova forma de se expressar e comunicar, repontando na forma de se produzir notícias e literatura.

Outra inovação presente é na abordagem do tema das viagens, tão caro aos modernistas. No caso de A. de A. M., destaca-se a postura irreverente e desabusada diante de países e paisagens venerados, tradicionalmente, pelos viajantes daqui. Adotando um relato conciso, incisivo e irônico, o cronista inverte a relação usual e demonstra as debilidades e os aspectos cômicos da Europa. O escritor viajante experimenta novos pontos de observação, seja pelo deslocamento acelerado, marca da modernidade; seja pela apreciação de outras paisagens, ampliando seu repertório de conhecimento e, por contraste, consegue refletir melhor sobre o próprio país.

$\mathrm{Na}$ ocasião da viagem de 1935, o escritor ocupava um lugar de grande destaque na cena cultural e política do país. Era diretor do jornal Diário da Noite, pertencente à cadeia dos Diários Associados de Francisco de Assis Chateaubriand Bandeira de Melo (1891-1968), e havia sido eleito como deputado federal, após intensa participação na Assembleia Constituinte de 1933.

A questão ideológica avulta e toma conta do cenário cultural em que, recordando Carlos Drummond de Andrade, vivia-se um "tempo de partido,/ tempo de homens 
partidos" (DRUMMOND, 1973, p. 82). O Modernismo, tal como surgiu com a Semana de Arte Moderna, havia chegado ao fim. Iniciava-se a "segunda fase modernista", voltada para a pesquisa social, sem a iconoclastia estética que caracteriza a chamada "fase heróica". Embora não possamos utilizar mecanicamente a divisão entre projeto estético X projeto ideológico (LAFETÁ, 1973, p. 23-24) para a primeira e a segunda fases, respectivamente; a literatura produzida na década de 1930, beneficiando-se das conquistas formais da década anterior, volta-se para o "problema brasileiro". Desse modo, observa-se uma mudança significativa nas obras de A. de A. M., cujos textos passam a se concentrar:

na exploração e desnudamento do Brasil, substituindo, não raro, o nacionalismo ufanista pela crítica pessimista. É o que podemos perceber através das crônicas de António de Alcântara Machado, mormente aquelas escritas na década de 30 . O pessimismo do autor quanto à realidade brasileira é patente. (ALMEIDA, 2001, p. 53, grifo da autora).

Voltando-se, mais detidamente, para as crônicas de viagem desse período, constata-se um equilíbrio entre a presença do experimentalismo na prosa e a mordente crítica do viajante modernista. As crônicas de viagem apresentam-se como o resultado do processo de sedimentação dos recursos formais e dos posicionamentos críticos que não chamam mais atenção por uma renovação impactante e iconoclasta. Deixa-se de lado a necessidade de marcar o território para o Modernismo e "outros valores mais altos se alevantam", alcançando-se uma maior simplicidade na prosa.

Destarte, são reunidas a visão mais cética sobre a realidade brasileira, contraponto importante para a apreciação de paisagens estrangeiras, e uma elaboração textual que não abandona, de todo, o humor e a renovação da primeira fase, ainda que a experimentação estética não seja a maior prioridade. Após esse breve retrospecto da trajetória modernista de A. de A. M. e a sua "prosa turística", vejamos a primeira escala da viagem à região do Rio da Prata.

\section{Primeira parada: "Montevidéu amável"}

A crônica de 12 de fevereiro de 1935 - publicada no jornal Diário da Noite descreve Montevidéu, a primeira cidade visitada pela comitiva, que permanece pouco tempo no local. Em um estilo "Kodak", são captados pequenos instantâneos do rápido 
contato com a capital uruguaia. A bordo de um automóvel, o cronista flagra cenas da urbe montevideana, fazendo-nos acompanhar o passeio pelas ruas e principais pontos turísticos. O périplo iniciado no porto, local de desembarque do navio Campana, vai até a orla de veraneio, a emblemática Rambla, símbolo arquitetônico da capital. A descrição se concentra em destacar a ordem, a higiene e a urbanidade de Montevidéu, imune aos abalos políticos e aos acontecimentos esportivos. Neste tópico, interessa-nos investigar até que ponto a percepção do cronista corrobora a imagem corrente acerca do país que se autodenominava a "Suíça da América" (GOMES, 2014, p. 93).

A visão do Cerro, cuja menção remete à fundação da cidade, é o ponto de partida do passeio. Contudo, tão indiferente quanto a paisagem remanescente do passado colonial, que parece não ter mais influência no presente, é a repercussão dos acontecimentos políticos na vida dos cidadãos uruguaios. Assim como o Brasil e a Argentina, o Uruguai se encontrava em um regime ditatorial (1933-1938) decorrente de um golpe político. A insurgência contra essa condição não parece incomodar, nem o partido no poder, o Colorado, nem o ditador Gabriel Terra (1873-1942) de acordo com a reportagem publicada no jornal situacionista EI Pueblo:

Do outro lado o Cerro domina a cidade de muito baixo. Mas o Cerro não interessa. Há outro assunto bem mais palpitante: a revolução. Como vai a revolução? No dizer de El Pueblo (primeira página, seis colunas em negrito), "el movimiento fue vencido sin que las fuerzas regulares entraran realmente en acción.". E acrescenta com imenso desprezo: "Chirinada sin bandera ha bastado el ruído de unas cuantas bombas para ponerle término". No fundo a revolução como o Cerro também não interessa. Ninguém Ihe faz espontaneamente a menor alusão. $E$ as perguntas que chegam alarmadas pelos telegramas ficam sem resposta satisfatória. Visível que a revolução não preocupa Montevidéu. É como se não existisse. (MACHADO, 1983, p. 295).

Alude-se à dificuldade em obter informações acerca da tentativa de contraataque ao governo: "Assim, por mais que a gente se esforce, não obtém dados para qualquer reportagem política." (MACHADO, 1983, p. 295). O cronista relata o maior destaque dado pela imprensa à vitória da Copa do Mundo de Futebol. O clima festivo em torno do título, "o Uruguai é hoje todo do futebol" (idem), ajuda a reforçar a imagem de que os problemas políticos são de menor monta ou, praticamente, não existem. A "aparência" de tranquilidade na capital e a celebração da conquista do campeonato não possibilitam ao viajante perceber que o país passava por um período adverso, sentindo os efeitos negativos da crise econômica vivida naquele momento: 
Em síntese, meio a um mundo em crise - declínio do modelo liberal-democrático - que impactou fortemente a realidade uruguaia, dissiparam-se utopias diversas - desde "o país modelo" do reformismo radical até o retorno do modelo agro-exportador defendido pelos ganaderos (criadores de gado). [...] Em meados de julho de 1930, os uruguaios gritavam campeones em comemoração à conquista da Primeira Copa do Mundo de Futebol, sediada em Montevidéu. No entanto, os festejos do centenário e a vitória no Mundial não esconderam a situação de crise na América Latina, fosse econômica ou política. (GOMES, 2014, p. 84).

Captando o ritmo citadino, o cronista perscruta as novas sociabilidades que emergem no século $X X$ e trata da ascensão do futebol como diversão e, principalmente, como elemento identitário da nacionalidade, tomando, para si, a cena cultural. Assim, a conquista esportiva representa a excelência e qualidade do país, que começava a vivenciar uma queda no padrão de vida, do qual se orgulhava com "certa dose de vaidade pelos seus respectivos sucessos sociais e culturais" (GOMES, 2014, p. 93). Os epítetos hiperbólicos para se referir à conquista e aos jogadores ocupam as páginas do jornal e ajudam a sustentar o orgulho pátrio: "O Uruguai entusiasmado chama-os de Pizarros. São os novos conquistadores do Peru." (MACHADO, 1983, p. 296).

Porém, tanto o evento político, quanto o evento esportivo não provocam quebra na ordem do espaço urbano, o que causa admiração no cronista. A respeito da festa a ser feita para o recebimento dos "esforzados athletas" (idem), não há sinais de tal comemoração no centro de Montevidéu: "A comoção deve ser interior. Não se nota nada extraordinário." (MACHADO, 1983, p. 296).

Em seguida, o passeio prossegue para a região da orla que reforça, ainda mais, a sensação de calmaria e prosperidade, por meio da observação de bairros abastados da capital uruguaia, como Pocitos e Carrasco: "Hotéis, restaurantes, residências ricas." (MACHADO, 1983, p. 296). A enumeração de espaços de sociabilidade seletos é contrastada com uma nota de humor: "Tem um edifício branco que já foi necrotério. Depois a municipalidade o transformou em cabaré. Naturalmente o cabaré não atraiu nenhum ente vivo. De maneira que vai ser aproveitado em breve para museu oceanográfico." (MACHADO, 1983, p. 296).

O viajante desprende, por entre a aparente homogeneidade do espaço controlado e planejado, o dado curioso que possa trazer aspectos mais dinâmicos da vida na cidade. Procede de igual forma, quando comenta a "presença de Brasil", seja num café, ou num presídio: "Há um Café Tupinambá que dá uma presença de Brasil. [...] Aquela ilha se chama das Flores e é presídio político. Mais uma presença do 
Brasil." (MACHADO, 1983, p. 296). O olhar do cronista estabelece uma relação de reconhecimento e maior aproximação com a terra estrangeira ao se deparar com elementos que possam lembrar, positivamente ou não, a própria terra.

O passeio vai chegando ao fim quando, na Rambla, "a cidade surge alta e bonita" (MACHADO, 1983, p. 296). Ressaltam-se, mais uma vez, a cordialidade, ou o "ar amável", a riqueza e o asseio urbanos: "A cidade trabalha em silêncio. O luxo que tem é discreto, riqueza sem ostentação." (idem). A insistência em reiterar a ordem de Montevidéu se contrapõe à imagem construída pelo escritor paulistano, nas crônicas e contos em relação ao Brasil da década de 1930, visto como um lugar de política ineficiente e avesso à organização. Contudo, esse contraste ressoa mais intensamente na comparação com a Argentina. Seguimos para a última parada da viagem: Buenos Aires.

\section{Destino Final: Buenos Aires, "uma confusão organizada"}

O "viajante platino" tenta abarcar inúmeras dimensões constitutivas da Argentina, em especial, da cidade de Buenos Aires. A divulgação da realidade do país vizinho, alvo da missão organizada pelo jornal Crítica, é realizada na condição de um correspondente internacional, responsável por recolher informações de um espaço inacessível e desconhecido ao leitor. Descreve-se a população, a natureza, o quadro político da época e a organização urbana em três crônicas: "Onde o homem o é" (21/02/1935, Diário de São Paulo; 26/02/1935, O Jornal); "Sobre Política Argentina" (22/02/1935, O Jornal; 22/02/1935, Diário de São Paulo) e "Primeira Impressão de Buenos Aires" (26/02/1935, O Jornal).

Chega-se à Argentina com a crônica intitulada "Onde o homem o é". No texto, sobressai a segregação na sociedade argentina, a discriminação racial e a capacidade do povo para lidar com uma "natureza avara". A ausência de miscigenação no país é interpretada, na crônica, como um processo seletivo, repontando o eugenismo e o darwinismo social que, desde o fim do século XIX, dividia o mundo em raças fortes e fracas. Nessa crônica, o escritor se vale de uma ambígua linha irônica que foi interpretada, por vezes, como aquiescência ao desejo de "branquear" a população, existente também no Brasil: 
Isso porque, mesmo recalcado, o ideal do embranquecimento crescente do brasileiro parece ter sempre estado subjacente ao sonho modernista: Macunaíma nasce preto, mas assim que pode se torna branco. Estaria aí uma das razões inconfessas da empatia de Alcântara Machado pelos novos mamalucos... brancos? É pergunta que permanece em aberto e quem se disponha algum dia a fechá-la não poderá dispensar-se de ler, em Cavaquinho e Saxofone, os três artigos em que o autor anotou suas entusiasmadas impressões da Argentina. (PAES, 1988, p. 106).

Longe de fecharmos a pergunta do crítico acerca da predileção pelos "mamalucos... brancos", concordamos que o traço caricatural presente na obra de A. de A. M. é muito forte e vai mais longe do que a simples troça, conforme o próprio José Paulo Paes aborda no artigo. Pensamos que a enunciação irônica do escritor paulistano decalca o pensamento reacionário para melhor desmascará-lo e, no perigoso fio da navalha em que a ironia desliza, nem sempre o efeito de dubiedade é percebido ou mesmo logrado imediatamente. Como exemplo dos problemas gerados pela leitura literal de seus textos, que estão nesse frágil equilíbrio, trazemos, rapidamente, um caso relatado por Assis Chateaubriand, quando o jornalista adota igual procedimento ao escrever uma coluna com o ponto de vista do P.R.P.:

\footnotetext{
Em 1929, decidiu pôr no queixo as barbas veneráveis do Sr. Washington Luis, e, pela mão enigmática do Rodrigo, estreou n'O Jornal uma secção que foi um acontecimento de estridor: $O$ ponto de vista do P.R.P. Era em julho daquele ano. Pleno abril da campanha liberal. Toda a gente supôs que se tratava de um encanizado e truculento perrepista. O seu disfarce era completo. Os srs. Antonio Carlos e João Neves queriam saber quem era aquele intruso, que defendia, na nossa maior tribuna liberal, o P.R.P. moribundo para o poder. E ninguém atinava que fosse uma boutade de Antonio Malazarte. (CHATEAUBRIAND, 1936, p. 15-16).
}

O texto, publicado anonimamente, foi recebido como uma defesa verdadeira do partido conservador paulistano nas páginas do jornal liberal de Assis Chateaubriand. Logo, a boutade ou o dito espirituoso e imprevisto, que contraria, de forma proposital, uma verdade ou conceito socialmente aceito, pode ser considerado um recurso corrente do escritor. Mesmo em tempos adversos, o artista não abandonou o humor, para ele uma qualidade importante a ser cultivada no jornalismo e na literatura. Em sua concepção, a gravidade excessiva não confere, necessariamente, ao texto mais verdade e seriedade.

Voltando à primeira crônica sobre a Argentina, seu início é uma rápida anedota que põe, em flagrante oposição, dois grupos formadores da sociedade rio-platense: o índio e o criollo. Ao narrar o caso do pedido frustrado de casamento feito por Victorino de la Plaza, "um índio autêntico e feio" (MACHADO, 1983, p. 297), a uma das filhas 
de D. Vicente Casares, "senhor rural de boa estirpe" (idem), açula-se o preconceito racial presente na Argentina.

A equiparação da seleção de "raças humanas" para a família à escolha de raças para o rebanho de gado pelo senhor de "boa estirpe", permite ao cronista expor o caráter discriminatório presente na ideia de aperfeiçoamento racial, que vigorava na Argentina e no restante do mundo daquele tempo: lembremos do nazismo já consolidado e do integralismo em terras brasileiras. Na dúbia enunciação, assume-se a voz daquele que discrimina para demonstrar a abominação existente em relação à mistura com as "raças fracas". Inclusive, o "busílis" para os modernistas, ou seja, a questão do negro (PAES, 1988. p. 106), é abordada pelo escritor nessa crônica. O jornalista lembra o repúdio que grande parte da população brasileira sofre, na Argentina daquela época, por ser miscigenada:

Como faz com relação ao gado, o homem da Argentina tem a preocupação de apurar cada vez mais a raça. A varíola que aqui matou os africanos serviu uma aspiração nacional. O branco não quer se tisnar de negro nem de amarelo e repele com indisfarçável repugnância, convencido de sua superioridade, a parte negra e mulata da população brasileira. Em oito dias de Buenos Aires só vi um preto argentino. (MACHADO, 1983, p. 297).

E, repentinamente, passamos à descrição da "raça de ombros largos", formada pelo sangue europeu, que "não desmerece o boi e o cavalo que the povoam os campos." (MACHADO, 1983, p. 298) e que traz o terceiro elemento de formação da sociedade argentina. As considerações seguem numa clave problemática, afinal, esses deveriam ser os textos da "missão cultural", que visava estreitar laços entre os dois países. E como realizar este intento, com uma crítica contundente a aspectos pouco apreciáveis do país vizinho?

O elogio que se segue parece amenizar a crítica realizada nos parágrafos iniciais, porém deixa entrever, novamente, o problema da discriminação. Abordando a engenhosidade que transformou os "charcos em palácios" e que sabe aproveitar os gozos mundanos, prossegue-se a equiparação entre humanos e animais. $O$ tipo argentino identificado é o "macanudo", descendente de espanhol ou italiano, de robusta compleição física e sensual:

Aqui o amoroso (ou o que se enfeita com esse nome) é desabusado, detesta as preliminares, diz o que quer. E objetivo e realista. Os jantares são ruidosos come-se muita carne, bebe-se muito vinho do Rio Negro, ri-se muito, conta-se muita anedota. E gasta-se muito dinheiro. Não há definir o argentino crioulo, ascendência andaluza, macho gozador da vida, folgazão, 
esplendidamente animal, senão com a palavra que exprime a sua admiração pelo que é bom e forte: "macanudo". (MACHADO, 1983, p. 298, grifos nossos).

A expressão de admiração vem acompanhada, assim, de termos e expressões do campo semântico da animalidade, pejorativos e que se chocam com o outro campo semântico construído, o da humanidade. Este é representado, nos parágrafos seguintes, pela capacidade intelectual que consegue tirar proveito de uma terra inóspita, pouco propícia ao trabalho e ao lazer. A imagem que fica marcada é de uma população próspera, de apetites físicos intensos, representados pelo gosto em se alimentar, se vestir e praticar esportes: "Tem a paixão do futebol, das corridas de cavalo, do remo, do boxe, do tênis, da natação, sente-se bem ao ar livre." (MACHADO, 1983, p. 298).

Novamente, o futebol ganha relevância na composição da identidade, marcando o poder que os clubes já começam a apresentar, aglomerando multidões de torcedores e sócios: "Mas é no futebol que o delírio esportivo atinge o seu auge. $\mathrm{O}$ Boca Juniors, com 18 mil sócios a peso e meio por mês cada um, o River Plate, com pouco menos; o Racing e outros com 11 e 12 mil" (MACHADO, 1983, p. 298).

A chegada à Argentina não se dá nas movimentadas ruas de Buenos Aires, expressão da modernidade do país, mas pela sua região periférica, os rios que banham cidades como Luján e Las Palmas. A crônica percorre a região do Delta do Tigre e salienta a laboriosidade como o grande diferencial dessa população, explicando, em suma, o título da crônica. De certa forma, corrobora a própria visão do escritor sobre a essência da modernização e o que faz com que as nações consigam progredir: o bom aproveitamento dos recursos em atividades produtivas. Sem as benesses de uma natureza farta, registra-se o esforço humano em tornar o espaço da "terra pantanosa" em fonte de trabalho e lazer. Em vez de uma paisagem natural intocada, acedemos a um espaço feito pela obstinação, "onde o homem o é", ou seja, responsável por si e pela sua subsistência:

O homem construiu palácios no Delta, desenhou jardins, plantou árvores e goza intensamente na paisagem chata e feia aquilo que lhe emprestou. Tudo é fabricado, custou dinheiro, revela o engenho e o esforço humanos criando uma aparência de pitoresco para desafogo da atividade urbana. O prazer é mais um fruto do trabalho. Na terra que se dá a riqueza se nega a sombra. É pródiga sem ser maternal. (MACHADO, 1983, p. 299). 
A crônica seguinte, "Sobre Política Argentina", realiza um breve panorama da situação política da nação rio-platense e as articulações do rearranjo governamental, assim como as perspectivas de futuras eleições. É traçado o perfil de Hipólito de Yrigoyen, o presidente retirado do poder, como ponto de partida da crônica. Busca-se explicar ao eleitor os partidos litigantes e a trajetória do líder, descrito como "encarnação intransigente da democracia em terras argentinas" (MACHADO, 1983, p. 301).

Tecem-se considerações sobre a reversão no julgamento da figura do expresidente, que consegue eludir o ostracismo e volta a protagonizar a cena política argentina. Apesar de haver falecido dois anos antes, a lembrança de Yrigoyen parecia ser suficiente para reerguer o seu antigo partido político, a UCR (União Cívica Radical).

A crônica prossegue com as dissensões dentro da UCR sobre o possível candidato presidencial: Máximo Marcelo Torcuato de Alvear (1868-1942) e Honório Pueyrredon (1876-1945), demonstrando os acasos curiosos da vida política. O jornalista assinala o favoritismo de Alvear para as eleições de 1937 e os embates do Partido Democrata Nacional, como reação ao crescente prestígio da UCR, apoiada pela sombra de Yrigoyen. O partido situacionista, contudo, não permanece estático diante da ameaça de perda da presidência: "Na Casa Rosada, sem beleza e sem conforto, o presidente Justo manobra com astúcia." (MACHADO, 1983, p. 304).

Dois anos depois, conhecem-se os resultados da "manobra": o novo pleito eleitoral é marcado por fraudes, que retiram a vitória da UCR. Ao fim, mencionam-se as dificuldades em obter a estabilidade institucional, pela ausência de coerência nas alianças políticas. Os comentários acerca da capacidade de tornar antigos aliados em inimigos, no caso, Alvear e Leopoldo Melo, encerram o texto: "Na política argentina, como em todas as políticas, há desses acasos irônicos." (MACHADO, 1983, p. 304).

A última crônica, "Primeira impressão de Buenos Aires", é a descrição da chegada, enfim, à capital da Argentina. Após tratar dos aspectos naturais, raciais e políticos do país, realiza-se o retrato de Buenos Aires. Chegamos através do Rio da Prata, "estuário barrento", cujo entorno plano, chama a atenção do cronista pela perspectiva descoberta, "horizontal". As amplas paisagens naturais tornam-se um símile das pródigas oportunidades aos recém-chegados. Retomam-se os tópicos 
explorados nas outras crônicas, como a natureza pouco atrativa compensada pela engenhosidade da população, cujo empenho transforma o espaço inóspito em cidade multitudinária e avançada. Buenos Aires é a personificação dessa laboriosidade:

Foi o homem que ergueu a cidade tão alto. Porque a natureza lhe negou qualquer pedestal, o chão estendido como um tapete prolonga o estuário barrento. Assim Buenos Aires se ergue nos próprios pés, cresce no campo chato. E por ele se alastra. Fim de linha, mistura de raças, confluência de dois rios e mil esforços. Aqui as ambições chegam esfomeadas e no chão fácil de palmilhar se saciam. A terra é mais que acolhedora: é aberta, não se esconde atrás de montanhas, se oferece toda. Horizontal. (MACHADO, 1983, p. 307).

Retoma-se, também, o primeiro sentido da palavra capital: cabeça. Buenos Aires é o centro de comando do país, cujos membros a seguem no mesmo esforço de ordem e trabalho. Mais adiante, ajustando o foco de observação, o cronista retoma o que "interessa": a urbanização de Buenos Aires. Vivencia-se um desnorteamento na primeira observação desse espaço citadino. Diferente de Montevidéu, cuja ordem é inalterável, sendo contraposta apenas pelo expressionismo da descrição do viajante modernista; Buenos Aires emerge como experiência de múltiplas sensações. A cidade portenha é dinâmica, movimentada, com cores, formas, aromas e sons que recordam um amálgama de outras cidades percorridas pelo cronista:

É Gênova que ressurge na Boca; italianos bigodudos cuspindo nas esquinas, pelas ruas sujas um cheiro de comida feita no óleo, tascas onde a gente do porto reata num momento relações antigas, crianças correndo nas calçadas e entendendo-se no dialeto da Superla. Depois há qualquer cousa de Barcelona na avenida larga como uma Rambla que conduz da Dársena norte ao centro da cidade, a avenida Leandro. [...] Depois é Paris, Paris sem dúvida nenhuma, repetidamente em Santa Fé, em Corrientes, em Callao, nos prédios a Luiz isto e aquilo, portais imponentes, grandes costureiros, um ar asseado de luxo, muito luxo, automóveis milionários, ao fundo o colar de pérolas da dona, ao lado do motorista o cachorro felpudo, enfastiado, snob também. (MACHADO, 1983, p. 307-308).

Mais adiante a comparação com a cidade de São Paulo torna-se inevitável, pois além de ser ponto de referência de A. de A. M., ambas as capitais viviam uma escalada de cosmopolitismo ocasionada pela grande imigração europeia ocorrida entre o fim do século XIX e o início de século XX. Consoante ao tom mais pessimista da década de 1930, são os aspectos menos atrativos da cidade de Buenos Aires que fazem o cronista lembrar-se de sua terra natal. A "face fabril e febril" da busca incessante de lucro e de integração à sociedade, os bairros periféricos de estrutura feia e precária são os pontos que recordam a capital paulista: 
Gênova, Barcelona, Paris, a enumeração poderia continuar. Até São Paulo, São Paulo, das casas baixas, dos bairros que se pensa no pão de cada dia. São Paulo fabril e febril. São Paulo das ruas sem árvores, um ventinho apressando o passo dos homens de mangas arregaçadas, turcos e italianos, espanhóis e eslavos (só faltam os japoneses) se esfalfando para que os filhos possam ingressar na alta sociedade. São Paulo, feio, construído sobre terrenos vendidos a prazo longo, até São Paulo aparece aqui e ali na parte sul de Buenos Aires, caminho de La Plata. (MACHADO, 1983, p. 308).

O tema que o havia consagrado - a vida do operariado imigrante - perde o vigor e o otimismo, como um dos pontos de mutação positiva em São Paulo. A industrialização, como fonte do progresso paulistano, não ganha mais o olhar utópico dos primeiros textos. Em contrapartida, o cronista confere à Buenos Aires uma capacidade integradora, que conseguiria lidar melhor com os aspectos menos convidativos da modernização: "Por maior que seja o poder de absorção da terra, porque ela é lisa, capaz de todas as mutações, aberta a todas as influências, nada repele, tudo the assenta bem." (MACHADO, 1983, p. 308).

A busca da "cor local" da Argentina só pode ser realizada em região mais afastada, no interior do país, onde ainda se guarda o resquício colonial, a origem "inamolgável". Embora na capital haja "uma confusão de raças, estilos, de culturas e civilizações", o desfecho da crônica reforça a questão da organização do espaço urbano portenho, a prosperidade da maioria da população, representada pela fartura na alimentação e participação em muitas atividades de lazer:

\begin{abstract}
Buenos Aires é, entretanto, uma confusão organizada, se faz em ordem, com trepedição mas sem atropelo. Um dinamismo disciplinado, uma alegria policiada. Embora para os lados do Puerto Nuevo ainda haja casinholas improvisadas para os sem-trabalho, o número de desocupados é mínimo. [...] Não há briguentos nem bêbados. Os salários altos garantem um nível de vida em que o trabalho e a diversão se alternam com regularidade. [...] No inverno trinta e oito teatros funcionam cheios. $E \mathrm{o}$ ano todo centenas de cinemas engolem multidões. A cidade come bem, vive bem, veste-se bem. E não há como estranhar e muito menos censurar esses prazeres seus de nova-milionária. Se sabe ganhar, sabe gastar. E se interessa pelas coisas do espírito. Aqui o homem fez tudo. Já organizou uma nacionalidade. Há de saber construir uma cultura. (MACHADO, 1983, p. 308-309).
\end{abstract}

A "primeira impressão", e última, que o viajante modernista deixa registrada é de uma Buenos Aires imune à crise política, ideológica e econômica tão forte e abrangente de meados da década de 1930. Conquanto existam ressalvas no que tange à questão racial e à organização política, sujeita a "manobras", o ritmo dinâmico de Buenos Aires e sua vocação pulsante para o progresso não são prejudicados pela aceleração urbana e pelos infortúnios dos desvalidos, uma parcela, aparentemente, mínima para o observador da cidade. O fim da crônica, e a conclusão da viagem, 
marca uma importante formulação política e ideológica para o escritor, que traça uma oposição entre o conceito de nacionalidade e o de cultura.

Conforme se depreende da crônica, o país platino havia alcançado um nível de estabilidade financeira e organizacional do espaço, assegurando a continuidade das principais características responsáveis pela construção da nacionalidade. Por outro lado, a conquista da cultura é o próximo passo para o país. Segundo o escritor modernista que, ao fim, não compreende positivamente o processo de receptividade e incorporação de traços de outros povos, e torna-se tributário do conceito de cultura como uma expressão simbólica inata e peculiar de um povo.

Para efetuar o contraste entre a visão do modernista brasileiro e a forma como se compreendia "o aspecto cosmopolita se acentua singularmente, grita em tudo, homens e cousas" (MACHADO, 1983, p. 308) na cidade de Buenos Aires, passamos ao último tópico do nosso percurso à região do Rio da Prata. Vejamos como o jornalismo argentino, representado na figura emblemática do jornalista Roberto Arlt, registra e analisa a cidade de Buenos Aires, centro da "cultura de mescla".

\section{A corrosão arltiana como contraponto à "confusão organizada"}

A visão de A. de A. M., baseada na busca da singularidade como marca identitária para o país, um dos fulcros do nosso Modernismo, perpassa seu relato sobre a região do Rio da Prata. O modernista fica dividido entre a exaltação ao progresso observado, propulsado pela composição cosmopolita da população, e a futura construção de uma cultura, quando os elementos que formam a nacionalidade argentina se fixassem e constituíssem uma "civilização". Acerca desse processo, Beatriz Sarlo examina a formação de um mercado cultural e expõe o embate, ligado às tensões sociais, que o acompanha:

Conflitos sociais espalham seu fantasma sobre os debates culturais e estéticos. A questão da língua (quem fala e escreve um castelhano "aceitável"); das traduções (quem está autorizado e por quais motivos a traduzir); do cosmopolitismo (qual é o internacionalismo legítimo e qual perverte as tendências que falsamente se reivindicam universais); do criollismo (quais formas respondem à nova estética e quais aos desvios pitorescos e folclóricos); da política (qual é a posição da arte diante das grandes transformações, qual é a função do intelectual, o que a responsabilidade pública dos escritores implica) são alguns dos temas presentes no debate. (SARLO, 2010, p. 55). 
Ao contrário da visão do cronista brasileiro, que percebe essa dicotomia como ausência de cultura, ou cultura a ser conquistada, Beatriz Sarlo demonstra um processo mais complexo e elaborado de disputa no mercado de valores simbólicos, constituindo em si, uma forma de perceber e construir as práticas culturais do país. Trata-se da formulação do conceito de cultura de mescla, que segundo a autora, é traço constitutivo da Argentina e que surgiu no momento das radicais transformações socioeconômicas ao princípio do século XX, cujo maior palco foi a sua capital, Buenos Aires:

$\mathrm{Na}$ verdade, uma hipótese que tentarei demonstrar apresenta a cultura argentina como uma cultura de mescla, em que coexistem elementos defensivos e residuais junto com os programas renovadores; traços culturais da formação criolla ao lado de um processo descomunal de importação de bens, discursos e práticas simbólicas. [...] A mescla é um dos traços menos transitórios da cultura argentina: sua forma já "clássica" de resposta e readaptação. O que um historiador da arquitetura chama de versatilidade e permeabilidade da cultura portenha me parece um princípio global de definição de estratégias ideológicas e estéticas. (SARLO, 2010, p. 56-57).

Justamente, são esses aspectos contraditórios que povoam as páginas de jornais como o periódico Crítica, organizador da "missão intelectual" brasileira na Argentina. Ao mesmo tempo em que se vive o deslumbramento com a adesão às novidades e avanços técnicos, da urbanização que torna Buenos Aires uma soma de várias capitais europeias, sobressaem, na década de 1930, as desigualdades provenientes da crise econômica, que alijam uma ampla camada da população dos benefícios e prosperidade encontrados pelo cronista brasileiro.

As tensões sociais e culturais estão impressas nas páginas dos jornais. Em especial, a luta entre os conservadores, que projetam uma mítica origem nacional, e os novos setores provenientes da imigração, que ascendiam socialmente e buscavam a legitimação dentro da sociedade portenha. Nesse sentido, o jornalista Roberto Arlt, descendente de imigrantes, valendo-se de saberes e de uma expressão linguística consideradas de menor prestígio, torna-se o porta-voz dessa realidade desigual:

En medio de la crisis, la sensibilidad arltiana se agudiza en la percepción de los márgenes y las víctimas de la transformación. Conciente del poder de su escritura y del valor que le otorga poseer una firma reconocida, asume como propia la tarea de denunciar una modernización que se juzga despareja. (SAÍTA, 2005, p. XII).

O jornalista, interessado pelas "orillas" da cidade, percorre ruas, passagens, boliches e praças menos resplandecentes, desprovidas do encanto da modernização 
avassaladora que tanto chamou a atenção do modernista brasileiro. Em vez de amplas perspectivas, símile da terra que "se oferece pródiga", e da iluminação feérica registradas por A. de A. M., adentramos em espaços estreitos, obscuros que são o símile da falta de oportunidade, das dificuldades enfrentadas por quem não consegue se integrar à grande metrópole:

Las veredas son tan estrechas y en las zonas anchas hay tantos escombros, que la gente va haciendo malabarismos con los pies entre los guardabarros de los autos. Como en los escenarios de los teatros cuando ya se apagaron las luces y quedan solas las bambalinas, se ven casas cortadas por la mitad, salones donde la piqueta municipal ha dejado íntegro, por un milagro, un rectángulo de papel de oro o una estampa de "La Vie Parissien". (ARLT, 2005, p. 45).

Surge uma Buenos Aires sem o luxo parisiense dos bairros nobres, babélica, contudo sem os elementos que emprestem uma organização à "bagunça" de cidade "fabril e febril":

El cambio urbano posterior a la crisis del treinta, repercute en la escritura arltiana politizando su mirada sobre la ciudad. Asume el rol de periodista denunciante que, proveniente quizá de su paso por el diario Crítica, transforma a su columna diaria en un medio eficaz para presionar sobre los sectores de poder. [...] De este modo, y por denuncias que se acumulan en su mesa de redacción, Arlt descubre un universo de pobreza y miseria que convive silenciosa e invisiblemente con las deslumbrantes luces del centro. (SAÍTTA, 2005, p. XIII).

A população observada é composta pelos provincianos perdidos em meio à agitação urbana, os desempregados, os pobres que evitam as ruas luxuosas, como a Calle Florida, os "vagos", de imprecisos objetivos e definição. É a cidade das "recovas", esfarrapada, suja, sem as oportunidades fáceis para o recém-chegado, recinto em que a pobreza se faz mais acintosa:

Cuatro recovas tiene Buenos Aires, cuatro recovas que son el refugio de la pobretería, el escaparate de la vagancia, el museo de la pobreza; cuatro recovas que son como los cuatro puntos cardinales de la miseria humana; cuatro recovas que son el caldero de la roña, el paseo del mugre, el camino de la sordidez, el valle de los desarrapados, la Corte de los Milagros de la piojería cosmopolita, cuatro recovas y una sola tristeza: la de los bolsillos sin dinero, la de las mujeres sin rumbo, la de los inmigrantes sin esperanza, la de los vencidos sin refugio. (ARLT, 2005, p. 18).

A grande multidão caracteriza a metrópole, contudo não existem vínculos de solidariedade que assegurem a fraternidade entre as pessoas, o que torna a dimensão dos problemas pessoais, ainda mais angustiante:

Y es que, en verdad, para todo hombre desesperado, la ciudad es como un desierto donde no cabe esperar piedad ni socorro de nadie. [...] 
Nuestras plazas son las que más predisponen al suicidio. Son tan feas y tienen estatuas tan grotescas que, por no mirarlas, más de un infeliz se ha eliminado.

Esto lo escribiría Paul Morand; pero pensando seriamente, se comprende por qué la plaza es el último apeadero del desdichado. Su aridez, lo desamparado de ella, el espectáculo de los desechos humanos que se adormilan en los bancos, todo contribuye a exasperar el delirio de un hombre que se siente en la mala. (ARLT, 2005, p. 24-25).

Notamos, todavia, que a experiência arltiana oscila entre o fascínio que a modernização produz, conforme relata em uma das águas-fortes, na qual trata da impossibilidade de abandonar o ambiente urbano: "Yo hombre de la ciudad, sujeto que me encuentro perfectamente cómodo en los cafés humosos y en las bocacalles ensordecedoras con el estrépito de los 'claxons' y los letreros parlantes." (ARLT, 2005, p. 53).

Desse modo, a dimensão mítica que a noite adquire torna mais variada a experiência urbana. Seja na Calle Corrientes, "la calle vagabunda" (ARLT, 2005, p. 44), cujas luzes fantasmagóricas acendem desejos que outros espaços da cidade negam, ou pelos espaços mais sombrios, hospedagens pobres e taciturnas, onde: "Cada hombre, en la noche, lleva un problema. No se desafía impunemente el silencio, la oscuridad y el vacío sin que medien motivos." (idem, p. 59).

Ao acompanharmos o escritor argentino, Buenos Aires revela-se paradoxal. Destacando-se o processo de consolidação de novos padrões de sociabilidade e de tentativa de adaptação e inserção na mistura de luxo e escassez, adentramos, também, em um relato que vive, intensamente, a "cultura de mescla". A cidade surge como o lugar de errância, perdição e reencontro consigo mesmo.

\section{Considerações finais}

De acordo com o percurso traçado ao longo de nosso estudo, percebemos uma dinâmica complexa - cultural, social e política - que forma a tentativa de aproximação das "pátrias de Sarmiento e Euclides da Cunha" (HOHAGEN apud MACHADO, 1983, p. 294). A missão intelectual, formada pelos jornalistas brasileiros, ocorre em meio a uma década de fortes tensões ideológicas, acompanhada de uma crise política que atinge grande parte da América do Sul. Argentina, Brasil e Uruguai viviam regimes ditatoriais e imensas agruras econômicas.

No caso das crônicas de A. de A. M., podemos inferir que o caráter oficial da viagem não permite conhecer os aspectos negativos vividos pelos países vizinhos, 
sobressaindo a mensagem de organização metódica e de progresso incondicional. Pelo depoimento de Múcio Leão, a comitiva seria acompanhada e levada a eventos e reuniões, sugerindo pouca margem para um contato menos direcionado com a realidade dos países platinos.

Ainda assim, A. de A. M. registra a dificuldade em conseguir dados que esclarecessem, por exemplo, a situação política do Uruguai. O passeio fugaz não permite recolher informações que pudessem contradizer as notícias de jornais uruguaios, que atenuavam as insurgências contra o golpe militar e celebravam, fervorosamente, a conquista da Copa do Mundo de Futebol. A aparente calmaria vista nas ruas ajuda a sustentar a visão de uma "Montevidéu amável" e luxuosamente higiênica.

$\mathrm{Na}$ Argentina, destino em que o cronista permanece mais tempo, os aspectos negativos são mitigados nas crônicas, seja através do humor, que traz uma enunciação irônica para a questão da discriminação racial, seja pelo elogio à capacidade de trabalho da população, que supera as adversidades naturais. Buenos Aires, centro da modernidade argentina, é uma "confusão organizada". Amálgama cultural que lembra várias cidades europeias e, inclusive, a São Paulo operária e periférica, a capital portenha, entretanto, é a personificação da laboriosidade do país. O que pode existir de negativo não produz grande impacto à imagem de fartura ordeira, da capital que usufrui os lazeres da modernidade. São atenuados tanto o cosmopolitismo acentuado, que não concederia uma face autêntica ao país; quanto os arrabaldes e desprestigiados do processo de modernização, que acrescentam seu quinhão de pobreza à cena urbana.

Ao contrapormos a descrição dessa experiência, através das páginas dos jornais portenhos, em especial, por meio das águas-fortes de Roberto Arlt, percebe-se um processo distinto. Conforme destaca Beatriz Sarlo, a cidade de Buenos Aires vivia uma modernidade periférica, cujos aspectos contraditórios, reunindo elementos antigos e modernos, além da disputa de diferentes atores pela primazia do campo cultural, constituem o traço da cultura argentina, denominada pela autora de cultura de mescla. No caso do jornalismo feito por Roberto Arlt, vivenciam-se os aspectos menos luminosos da modernização, surgindo uma Buenos Aires, cujo poder de atração pode destruir os mais frágeis e menos capitalizados na tentativa de se integrar 
à grande cidade. Misto de Babel e deserto, a experiência arltiana aparece prenha de contrastes, desigualdades e sonhos que alimentavam o desejo da modernidade portenha.

\section{Referências bibliográficas}

ALMEIDA, A. S. de. Solos geniosos, de épocas turbulentas: crônicas de António de Alcântara Machado para o Diário da Noite. 2001. 334 f. Dissertação. (Mestrado em Letras, Área de Teoria Literária) - UNICAMP, Campinas, 2001. Disponível em: <www.bibliotecadigital.unicamp.br/document/?down=vtls000240114>. Acesso em: 17 jan. 2013.

ANDRADE, C. D. de. Reunião. 10 livros de poesia. 4. ed. Rio de Janeiro: José Olympio, 1973.

ARLT, R. Aguafuertes porteñas. Buenos Aires vida cotidiana. Seleção, prólogo e notas S. Saítta. 2. ed. Buenos Aires: Losada, 2005.

CHATEAUBRIAND, A. O comandante do submarino. In: MACHADO, J. de A. et al (Org.). Em memória de António de Alcântara Machado. São Paulo: Elvino Pocai, 1936, p. 15-21.

GOMES, R. N. Um ensaio sul-americano: as nossas primeiras aproximações das relações entre o Brasil e o Uruguai na década de 1930. Polis, Revista Latinoamericana, Volumen 13, № 39, 2014, p. 83-98. Disponível em: <https://scielo. conicyt.cl/pdf/polis/v13n39/art05.pdf>. Acesso: 05 jun. 2018.

LAFETÁ, J. L. 1930: a crítica e o Modernismo. Pref. de A. Candido. 2.ed. São Paulo: Duas Cidades, 1974.

LEÃO, M. Antonio de Alcântara Machado. In: MACHADO, J. de A. et al (Org.). Em memória de António de Alcântara Machado. São Paulo: Elvino Pocai, 1936, p. 134157.

MACHADO, A. de A. Pathé Baby e Prosa turística: o viajante europeu e platino. Org. C. de Lara. Vol. 2. Rio de Janeiro: Editora Civilização Brasileira, 1983.

Educ, 1997.

Pressão afetiva \& aquecimento intelectual. Org. C. de Lara. São Paulo:

PAES, J. P. Cinco livros do Modernismo brasileiro. Estudos Avançados, São Paulo, n. 3, vol. 2, p. 88-106, 1988. Disponível em: <http://dx.doi.org/10.1590/S010340141988000300007>. Acesso: 19 set. 2016.

SARLO, B. Modernidade periférica: Buenos Aires 1920 e 1930. Trad. e posfácio de J. P. Pinto. Prólogo de S. Miceli. São Paulo: Cosac Naify, 2010. 
SAÍTTA, S. Entrevista. In: ABDALA, V. Una investigación sobre el olvidado Diario "Crítica". El tábano de Natalio Botana. Página 12, Buenos Aires, 1998. Disponível em: <http:// www.pagina12.com.ar/1998/98-06/98-06-11/pag35.htm>. Acesso em: 14 ago. 2016.

\section{Sobre a autora \\ Mônica Gomes da Silva}

Graduada em Letras Português-Espanhol (2007) na Universidade Federal Fluminense. Mestre em Letras, Subárea Literatura Brasileira e Teorias (2010), bolsista CNPq, na mesma instituição. Doutora em Estudos Literários (2015) pela Universidade Federal Fluminense como bolsista ReUni. Atuação na modalidade Pré-Vestibular com as disciplinas Espanhol e Literatura Brasileira. Experiência docente em níveis Fundamental, Médio e Superior com as disciplinas Português, Espanhol e Literatura Brasileira e tutora a distância da disciplina Literatura Brasileira III pelo convênio CEDERJ-UFF. Atualmente, leciona Literatura Brasileira como Professora Adjunta na Universidade Federal do Recôncavo da Bahia. Participante e líder do Grupo de Pesquisa e Extensão LEIA (Leitura, Escrita, Identidade e Artes). Desenvolve pesquisas na área de correspondência literária e da relação entre leitura, literatura e a fruição estética. 